Published as: Kellens, W., Zaalberg, R. \& De Maeyer, P. (2012), The informed society: An analysis of the public's information seeking behavior regarding coastal flood risks. Risk Analysis, 32 (8), pp. 1369-1381.

\title{
The informed society: An analysis of the public's information seeking behavior regarding coastal flood risks
}

\author{
Wim Kellens, Ruud Zaalberg, Philippe De Maeyer
}

\begin{abstract}
Recent flood risk management puts an increasing emphasis on the public's risk perception and its preferences. It is now widely recognized that a better knowledge of the public's awareness and concern about risks is of vital importance to outline effective risk communication strategies. Models such as RISP (Risk Information Seeking and Processing) address this evolution by considering the public's needs and their information seeking behavior with regard to risk information. This study builds upon earlier information seeking models and focuses on the empirical relationships between information seeking behavior and the constructs of risk perception, perceived hazard knowledge, response efficacy and information need in the context of coastal flood risks. Specific focus is given to the mediating role of information need in the model and to the differences in information seeking behavior between permanent and temporary residents. By means of a structured on-line questionnaire, a cross-sectional survey was carried out in the city of Ostend, one of the most vulnerable places to coastal flooding on the Belgian coast. Three hundred thirteen respondents participated in the survey. Path analysis reveals that information need does not act as a mediator in contrast to risk perception and perceived knowledge. In addition, it is shown that risk perception and perceived hazard knowledge are higher for permanent than temporary residents, leading to increased information seeking behavior among the former group. Implications for risk communication are discussed.
\end{abstract}

\section{Key words}

coastal flood risk, risk communication, information seeking behavior, risk perception, path analysis 


\section{INTRODUCTION}

The last two decades have witnessed an increasing interest in research on risk perception and risk communication with regard to flood hazards. By determining and analyzing the opinion of the general public on flood risks and their preferences for mitigation measures and adjustments, risk perception research has gradually taken a definite position in flood risk management. ${ }^{(1,2)}$ In addition, the communication about these flood risks is evolving to strategies which enhance information-sharing, bottom-up activity and partnership development. ${ }^{(3,4)}$ In his White Paper on Risk Governance, Renn ${ }^{(5)}$ underlines the importance of adjusting risk communication to the specific needs of the people. As such, people are given the possibility to judge their own risk situation and to make informed decisions and actions regarding preparedness and personal safety measures.

In search for tools or means that enhance this self-protective behavior, a field of studies has focused on examining the determinants of information seeking behavior, which is generally acknowledged as an important precursor of self-protective behavior. ${ }^{(6-8)}$ Griffin and colleagues ${ }^{(9)}$ defined information seeking behavior as the effort to acquire information in response to a need or perceived gap in ones knowledge. Various models have been suggested to explain people's seeking behavior regarding risk information, such as the Risk Information Seeking and Processing model (RISP) ${ }^{(9)}$, the Framework for Risk Information and Seeking (FRIS) ${ }^{(10)}$ and the Planned Risk Information Seeking Model $(\text { PRISM })^{(11)}$. To date, only two studies have applied such models to flood risks. Griffin et al. ${ }^{(12)}$ adopted the RISP model and focused on citizen's feelings of anger at managing agencies. Kievik and Gutteling $^{(6)}$ employed parts of the FRIS model to test the effect of simple risk communication tools on people's seeking intentions and their self-protecting behavior. However, both studies contained limitations. Since Kievik and Gutteling ${ }^{(6)}$ focused on just two predictors of information seeking behavior (i.e., risk perception and efficacy beliefs), other important predictors or relationships remained out of scope. Griffin et al. ${ }^{(12)}$, from their part, did not test mediating relationships, although many are suggested in the proposed models.

Distinctive for the information seeking models is the central role for the level of information insufficiency or information need. Hence, the degree to which a person perceives information need is assumed to determine his/her seeking behavior. In turn, information need is determined by other predictors, such as individual and hazard characteristics, risk perception, efficacy beliefs, current knowledge, etc. The central position of information need in these theoretical models clearly suggests a mediating role in the information seeking process. ${ }^{(9,13)}$ However, past research did not fully succeeded in revealing the functioning of information need in information seeking behavior, neither in a health risk context ${ }^{(11)}$, nor in the context of flood risks ${ }^{(12)}$. Therefore, our first research objective concentrates on the mediating properties of information need in the information seeking process.

Understanding the determinants of individual flood adjustments is not only important in terms of damage reduction and individual welfare, it is also a sensible counterweight to the governmental focus on flood adaptation measures. For example, flood risks are receiving increasing interest on the Belgian coast, since various measures (such as beach nourishment, storm walls, etc.) are being carried out to protect the coast against future extreme storm surges from the North Sea (cf. Master Plan Coastal Safety $\left.{ }^{(14)}\right)$. To date, however, scarce attention has been given to citizens at risk and their information needs. One exception is the European COMRISK project ${ }^{(15)}$, which was conducted in 2004 (i.e., before the infrastructure works on the Belgian coast), and which revealed - among other things - that the Belgian public exhibits the highest demand for more information on coastal flood risks (78\%), as compared to several other European countries (i.e., Denmark, Germany, The Netherlands and United Kingdom). The Belgian coast is therefore an intriguing area to probe the public's seeking behavior with regard to coastal flood risk information.

Our second research objective is not only to extend our scientific knowledge on the public's attitudes regarding flood risks on the Belgian coast, but also to focus on a specific target group which is often completely overlooked in flood risk research, namely temporary residents. Several authors have suggested that this group of residents is more vulnerable to disaster situations than locals, because they are less familiar with local hazards and the resources that can be relied on to avoid risk. ${ }^{(16,17)}$ This 
is especially true for temporary residents who own a second home on the coast, here referred to as second residence owners. The fact that three quarters of the overnight tourism on the Belgian coast is based on second residence tourism ${ }^{(18)}$ signals its importance in terms of damage reduction and personal welfare in case of floods. The present study explicitly considers both permanent residents (inhabitants) and temporary residents (second residence owners) and examines possible differences in their risk information need and risk information seeking behavior.

In sum, this study builds upon previous information seeking models and contributes to a better understanding of the relationships between information seeking behavior and its main determinants in the context of coastal flood risks. Particular attention is given to the mediating relationship of information need and to the effects of residing permanently in a flood-prone area or not. Area of interest is the city of Ostend, which is known as one of the most vulnerable locations to coastal flooding on the Belgian coast. ${ }^{(19)}$

\section{THEORETICAL BACKGROUND}

\subsection{Overview of information seeking models}

The study of information seeking behavior has been the focus of the model of Risk Information Seeking and Processing (RISP), developed by Griffin and colleagues ${ }^{(9)}$. By adapting and synthesizing components from the Heuristic-Systematic Model (HSM) ${ }^{(20)}$ and the Theory of Planned Behavior $(\mathrm{TPB})^{(21)}$, the RISP model proposes that information insufficiency is the key factor that motivates people to seek for and process risk-related information. This information insufficiency is strongly correlated with hazard knowledge and is predicted by a set of factors, among which are individual characteristics (e.g., hazard experience) and risk perception (affective response).

Drawing further on the concepts of the original RISP model, ter Huurne and Gutteling ${ }^{(13)}$ proposed a framework which relates risk information seeking behavior to self-efficacy, current knowledge (about hazards), risk perception and information need. An adapted version of the model was later referred to as the Framework of Risk Information Seeking (FRIS). ${ }^{(10)}$ While RISP considers individual characteristics (such as age, gender and hazard experience), ter Huurne and Gutteling's model puts more emphasis on psychological characteristics, such as trust, self-efficacy and engagement as determinants of information seeking behavior. Applied to industrial risks and hazard waste transportation risks, ter Huurne and Gutteling ${ }^{(13)}$ found that information need, risk perception and current knowledge are direct predictors of the intention to seek risk information.

Kahlor ${ }^{(11)}$ brought several concepts from previous information seeking models together and formed the Planned Risk Information Seeking Model (PRISM), which treats risk information seeking as a deliberate (planned) behavior. Main components in this model are risk perception, affective risk response, perceived knowledge and perceived knowledge insufficiency. In contrast to earlier models, Kahlor $^{(11)}$ could not demonstrate a significant link between knowledge insufficiency and information seeking behavior.

Finally, a recent study of Kievik and Gutteling ${ }^{(6)}$ showed that information seeking behavior is particularly susceptible to levels of risk perception and efficacy beliefs. In an experimental study design, it was demonstrated that information seeking behavior (and hence self-protective behavior) can be stimulated with relatively simple risk communication tools that influence risk perception levels (by means of fear appeals) and efficacy beliefs (through message content). While this study did not test a comprehensive model, it showed the importance of risk perception and efficacy beliefs in the context of coping with flood risks.

Based on the above findings, several determinants of information seeking behavior and their relationships come to the fore as important or at least as interesting items to scrutinize. Information need (or insufficiency) is deemed an essential factor in each model, yet its mediating role remains unclear. ${ }^{(9,11,12,22)}$ Risk perception and efficacy beliefs are considered crucial predictors of information seeking behavior ${ }^{(6,13)}$, but their relationship with information need is insufficiently examined. Another 
determinant included in almost every model is (perceived) hazard knowledge. However, both its relation with information need as well as its predicting role on information seeking behavior are contested. ${ }^{(11)}$ Finally, several individual characteristics (e.g., age, gender, hazard experience) have been suggested in the original RISP model, but their actual influence in the complete information seeking process remains unsure. ${ }^{(9,12)}$ The next section discusses each of these determinants in more detail.

\subsection{Determinants of information seeking behavior}

Information need. Information insufficiency or information need plays a central role in the audiencebased risk communication approaches. ${ }^{(10)}$ It is widely regarded as the key motivator to seek for risk information. Based on the sufficiency principle in the Heuristic-Systematic Model ${ }^{(20)}$, Griffin et al. ${ }^{(12)}$ define information insufficiency as the perceived "gap" between current knowledge and sufficient knowledge (i.e. the threshold that one perceives as being sufficient). The less people know about a risk/hazard, or the higher their perception of the required knowledge level, the higher their need for risk-related information will be, and consequently their intentions to seek for additional information.

Perceived hazard knowledge. According to Griffin and colleagues, ${ }^{(12)}$ definition of information insufficiency, current or perceived knowledge is inherently part of insufficiency. Yet, others ${ }^{(11,13)}$ regard perceived knowledge as a separate variable that influences one's need for risk-related information. Lower perceived knowledge relates to higher information need and thus seeking intentions.

Risk perception. The study of the public risk perception has undergone a remarkable growth in the last decades, and is now represented in nearly every risk domain. While many elements have been related to risk perception ${ }^{(23,24)}$, some key elements have been generally used with regard to the prediction of information seeking behavior. Griffin and colleagues defined risk perception as the combination of subjective judgments of a hazard's probability with the perceived severity of possible consequences. ${ }^{(12)}$ They further demonstrated that risk perception influences affective responses to a hazard, such as feelings of worry or anger. ${ }^{(12,22)}$ These definitions correspond to the two modes of thinking in risk perception ${ }^{(25)}$, which distinguish between risk as analysis (analytical system) and risk as feelings (experiential system). While the former relies on normative rules and formal logic, the latter uses fast, intuitive decisions. Despite this theoretical distinction, several researchers have found a single risk perception scale, based on factor analysis. ${ }^{(\text {e.g. }}{ }^{19,26,27)}$ Risk perception (including affective response) is generally regarded as a positive predictor for information need, even though some studies have demonstrated the opposite relation. ${ }^{\text {(e.g. } 28)}$

Efficacy beliefs. Risk communication researchers have stressed the importance of considering one's belief that he or she is able to understand and execute certain actions to cope with a hazard. This concept is well-known as self-efficacy ${ }^{(13)}$, and its positive effect on information seeking intentions has been reported several times. ${ }^{(6,12,13)}$ Related to self-efficacy is response efficacy, which denotes the perceived usefulness of information (e.g., advice) to successfully cope with a threat. Previous research $^{(6)}$ has demonstrated strong correlations between self-efficacy and response efficacy, together referred to as efficacy beliefs. For reasons of simplicity, we will focus on just one type of efficacy in this study, namely response efficacy.

Individual characteristics. Socio-demographic variables are found in most studies of risk perception, but typically they are employed a-theoretically and account for relatively little explained variance in information seeking behavior. ${ }^{(9,22)}$ However, several studies have identified significant relations

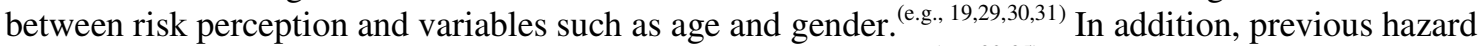
experience has generally been found to increase risk perceptions ${ }^{\text {(e.g. } 32-35)}$ and the likelihood that people

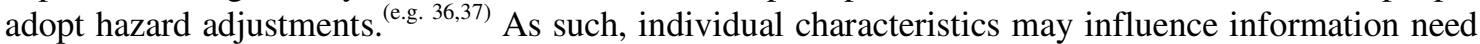
and information seeking intentions through risk perception. Griffin et al. ${ }^{(12,22)}$ also found effects of individual characteristics (e.g., education) on information need through perceived knowledge. To our knowledge, effects of residing permanently or temporary on a hazard-prone location have not yet been examined in the context of information seeking behavior. 


\section{RESEARCH HYPOTHESES}

Figure 1 depicts a theoretical model of information seeking behavior, which stems from the discussed determinants and their relationships in the previous section. In order to structure the analysis of the model, following hypotheses are defined:

$\mathrm{H} 1 \mathrm{a} / \mathrm{b}$ : individual characteristics (a) and response efficacy (b) predict information seeking behavior;

$\mathrm{H} 2 \mathrm{a} / \mathrm{b} / \mathrm{c}$ : risk perception (a), perceived hazard knowledge (b), and information need (c) mediate the H1a effect;

H3a: information need mediates the relationship between risk perception and information seeking behavior;

$\mathrm{H} 3 \mathrm{~b}$ : information need mediates the relationship between perceived hazard knowledge and information seeking behavior;

H4: individual characteristics predict information need;

$\mathrm{H} 5 \mathrm{a} / \mathrm{b}$ : risk perception (a) and perceived hazard knowledge (b) mediate the $\mathrm{H} 4$ effect.

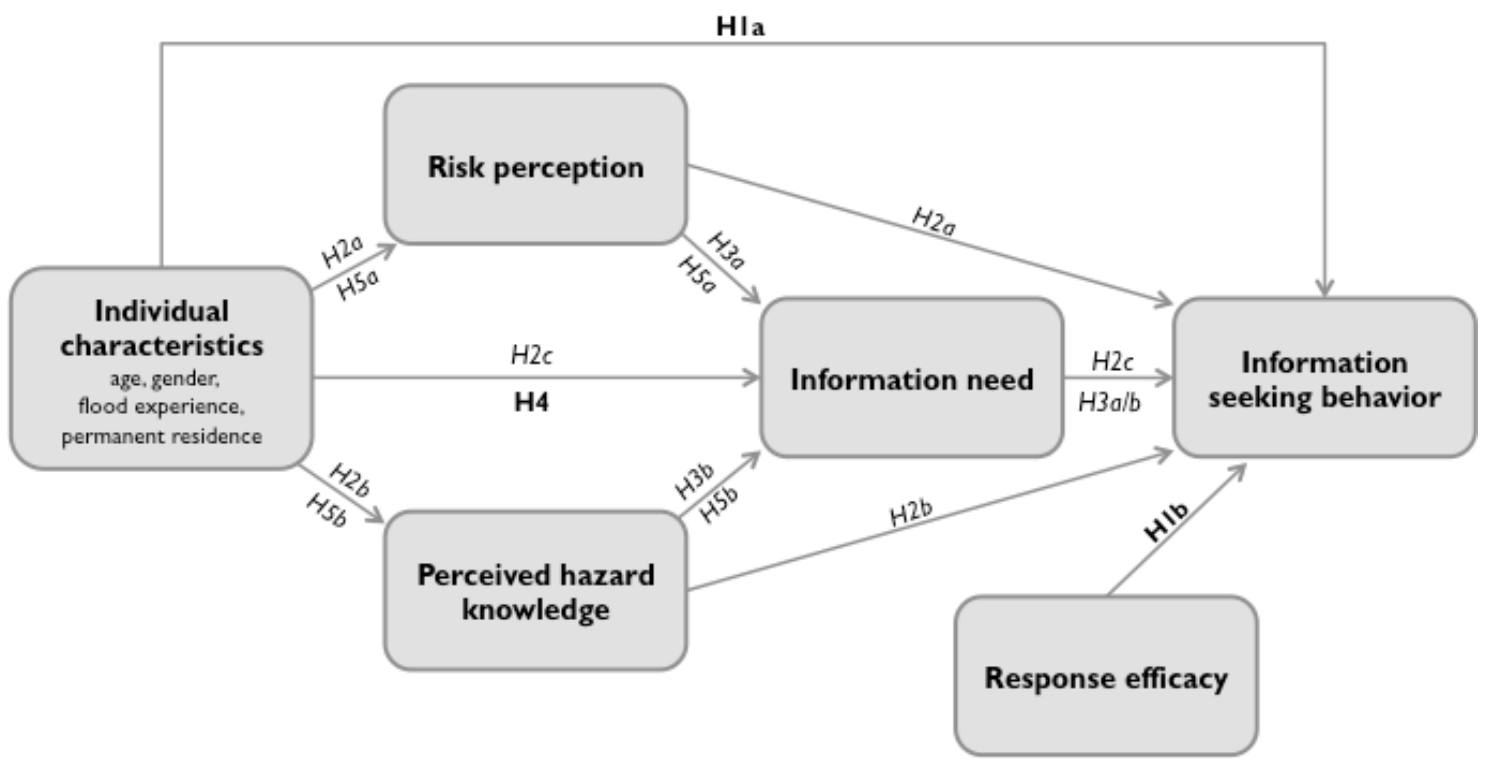

Figure 1 Hypothesized relationships among determinants of information seeking behavior.

Total effect relations ( $\mathrm{H} 1$ and $\mathrm{H4})$ are represented in bold; mediating relations $(\mathrm{H} 2, \mathrm{H3}$ and $\mathrm{H5})$ are represented in italic.

\section{METHODOLOGY}

\subsection{Study area and data collection}

Area of interest in this study is the city of Ostend, which lies in a central position on the $65 \mathrm{~km}$ long Belgian coast. The Belgian coast is located along the Southern Bight of the North Sea and is characterized by sandy beaches, dune areas and hard defense structures such as groynes and sea walls. 
Due to the limited length of the coastline and the increasing population pressure, most of the coastal zone has become urbanized and half of the coastal dunes has disappeared. ${ }^{(38)}$

In the past, several storm surges have affected the Belgian coast. During the severe storm flood disaster of 1953, eight people died in the city of Ostend. According to the outcomes of the on-going Master Plan for Coastal Safety ${ }^{(39)}$, the city centre of Ostend is still considered one of the most vulnerable parts of the Belgian coast. Even so, major efforts have been realized in the previous years with regard to beach nourishment and soft-sea defense structures.

With a population number of approximately 69,000 inhabitants, Ostend is by far the largest place on the Belgian coast. The number of temporary residents is estimated above 20,000 during "top days" in the summer holidays. Approximately $30 \%$ of this group is owner of a second residence. According to a recent study ${ }^{(18)}$, owners stay on average about 54 nights per year in their second residence.

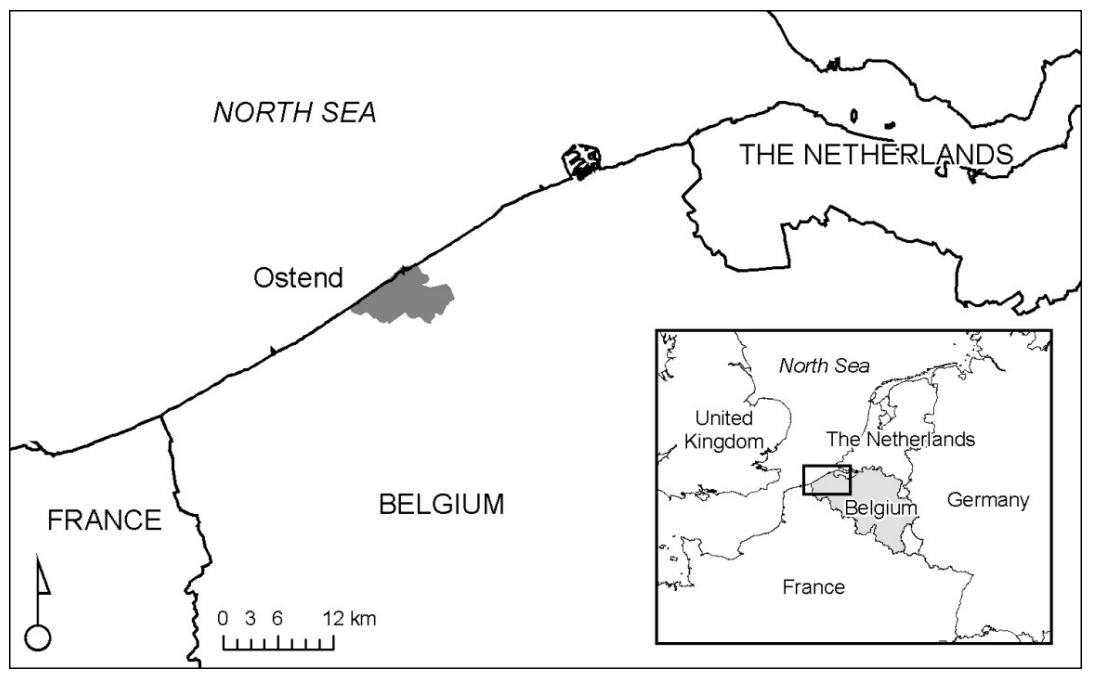

Figure 2 Location of Ostend on the Belgian coast

Data were collected during the month September 2010 by an on-line questionnaire, which was developed with the open source survey application LimeSurvey®. Adult permanent and temporary residents were invited to take part in the study through an invitation letter. These letters were systematically distributed in postboxes in a random selection of streets in the city of Ostend. Based on the outcomes of several worst-case scenarios (cf. Master Plan for Coastal Safety ${ }^{(14)}$ ), most of the territory of the city of Ostend can be regarded to be at risk of being (severely) flooded during an extreme storm surge. The belongings of all respondents are therefore assumed to be at equal chance of flooding.

\subsection{Questionnaire description}

Table I presents all items that were used to measure the model components as depicted in Figure 1 (except for individual characteristics), together with their item statistics (mean and standard deviation) and factor loadings (see Section 4.4.1).

In order to measure information seeking behavior, respondents were asked to what extent they intended to search for information on four topics, (i) possible consequences of a storm surge, (ii) measures that the government is employing to cope with storm surges, (iii) possible escape routes in case of threatening coastal floods, and (iv) safe locations in the neighborhood (scores 1 to 5, from "definitely not" to "definitely"). These topics are based on items to measure flood preparedness 
intentions, developed and used by Terpstra. ${ }^{(40)}$ Perceived hazard knowledge was measured by four questions related to: (i) the consequences of a coastal flood, (ii) the use and functioning of beach nourishment, (iii) the protection level of the dikes and (iv) the maintenance of the sea defence. All four questions were introduced by "How well do you think you're informed about...?" and answers ranged from "very bad" (score: 1) to "very good" (score: 5). Risk perception was measured through five items, which were based on previous research on public perceptions of coastal flood risks. ${ }^{(19)}$ The five items reflect different aspects of risk perception: awareness (or consciousness), likelihood, affect (worry), impact (storm surge consequences) and calmness (feeling safe). All items were measured on a 5-point scale, ranging from "no agreement at all" (score: 1) to "full agreement" (score: 5). Response efficacy was measured by the perceived level of usefulness of three information topics, (i) the sea defense and the actual protection level, (ii) tips and instructions on personal measures to mitigate flood damage and (iii) instructions about evacuation procedures and escape routes (scores 1 to 5, from "not useful at all" to "very useful"). Finally, information need or information insufficiency was measured by three dichotomous questions, (i) "Do you think sufficient information is provided about the flood risks on the Belgian coast?", (ii) "Have you ever searched for information about flood risks on the Belgian coast?", and (iii) "Would you like to know more about flood risks on the Belgian coast?" (yes/no, coded as 1/0).

A closer look at the item statistics in Table I reveals remarkably high values for the items measuring information need. Particularly the question "Would you like to know more about flood risks on the Belgian coast?" results in a manifest mean score of 0.92 (in which "no" = 0; "yes" = 1). Hence, 92\% of our sample indicates that more information on coastal flood risks is necessary.

Finally, a small set of individual characteristics was gathered. Apart from age, gender (male/female, coded as 1/0), permanent and temporary residents were distinguished from each other by the question "Do you reside permanently on the Belgian coast?" (yes/no, coded as 1/0). Flood experience was measured by a dichotomous question "Have you ever suffered material and/or financial damage as a consequence of flooding (be it on the coast or elsewhere)?" (yes/no, coded as $1 / 0$ ). 
Table I Overview of all questionnaire items with their factor loadings and item statistics

\begin{tabular}{|c|c|c|c|c|c|c|}
\hline \multirow[t]{2}{*}{ Items } & \multicolumn{4}{|c|}{ Factor loadings } & \multicolumn{2}{|c|}{ Item statistics } \\
\hline & I & II & III & IV & Mean & SD \\
\hline 1. Information seeking behavior $(\alpha=0.89)$ & & & & & 13.98 & 3.60 \\
\hline \multicolumn{7}{|l|}{$\begin{array}{l}\text { To what extent do you intend to search for more information } \\
\text { on: }\end{array}$} \\
\hline - possible consequences of a storm surge; & 0.83 & & & -0.21 & 3.42 & 0.93 \\
\hline $\begin{array}{l}\text { - measures that the government is employing to cope with } \\
\text { storm surges; }\end{array}$ & 0.87 & & & & 3.61 & 0.96 \\
\hline - possible escape routes in case of threatening coastal floods; & 0.75 & & & 0.33 & 3.40 & 1.10 \\
\hline - safe locations in the neighborhood. & 0.70 & & & 0.31 & 3.41 & 1.14 \\
\hline 2. Perceived hazard knowledge $(\alpha=0.94)$ & & & & & 9.86 & 4.08 \\
\hline \multicolumn{7}{|l|}{ How well do you think you're informed about...? } \\
\hline - the consequences of a coastal flood; & & 0.81 & & & 2.42 & 1.12 \\
\hline - the use and functioning of beach nourishment; & & 0.91 & & & 2.74 & 1.20 \\
\hline - the protection level of the dikes; & & 0.95 & & & 2.55 & 1.11 \\
\hline - the maintenance of the sea defense. & & 0.87 & & & 2.40 & 1.09 \\
\hline 3. Risk perception $(\alpha=0.78)$ & & & & & 15.65 & 3.76 \\
\hline $\begin{array}{l}\text { - I sometimes give flood risks on the Belgian coast a moment } \\
\text { thought. (awareness) }\end{array}$ & & & 0.63 & & 2.46 & 0.96 \\
\hline $\begin{array}{l}\text { - I expect great chances of storm surges causing floods in the } \\
\text { coastal area. (likelihood) }\end{array}$ & & & 0.77 & -0.11 & 3.24 & 1.13 \\
\hline $\begin{array}{l}\text { - I'm worried about the danger of a storm surge on the } \\
\text { Belgian coast. (affect) }\end{array}$ & & & 0.90 & & 3.08 & 1.20 \\
\hline $\begin{array}{l}\text { - A storm surge can have fatal consequences for the coastal } \\
\text { area and its inhabitants. (impact) }\end{array}$ & & & 0.51 & & 3.78 & 1.02 \\
\hline $\begin{array}{l}\text { - When I stay on the Belgian coast, I feel protected by the } \\
\text { sea defenses. (calmness)* }\end{array}$ & & 0.19 & -0.36 & & 3.37 & 0.95 \\
\hline 4. Response efficacy $(\alpha=0.74)$ & & & & & 8.16 & $\mathbf{1 . 8 7}$ \\
\hline \multicolumn{7}{|l|}{$\begin{array}{l}\text { To what extent may the following information topic be } \\
\text { useful to you: }\end{array}$} \\
\hline - the sea defense and the actual protection level & 0.12 & & 0.13 & 0.14 & 4.06 & 0.79 \\
\hline $\begin{array}{l}\text { - tips and instructions on personal measures to mitigate flood } \\
\text { damage }\end{array}$ & & & & 0.55 & 3.96 & 1.12 \\
\hline - instructions about evacuation procedures and escape routes & & & & 0.98 & 4.10 & 1.07 \\
\hline 5. Information need $* *$ & & & & & 2.12 & 0.51 \\
\hline $\begin{array}{l}\text { - Do you think sufficient information is provided about the } \\
\text { flood risks on the Belgian coast?* }\end{array}$ & - & - & - & - & 0.16 & - \\
\hline $\begin{array}{l}\text { - Have you ever searched for information about flood risks } \\
\text { on the Belgian coast? }\end{array}$ & - & - & - & - & 0.22 & - \\
\hline $\begin{array}{l}\text { - Would you like to know more about flood risks on the } \\
\text { Belgian coast? }\end{array}$ & - & - & - & - & 0.92 & - \\
\hline
\end{tabular}

\subsection{Sample characteristics}

A total of 313 respondents filled out the questionnaire, leading to a response rate of $6.3 \%$. While a low response rate is not unusual for on-line questionnaires, the sample's representativeness might become uncertain if the nonresponse is systematic rather than random. ${ }^{(41)}$ However, as Lindell and Perry ${ }^{(42)}$ indicate, a low response rate does not constitute a significant obstacle to drawing statistical conclusions on such data. Based on the 251 permanent residents (79.4\%) against the 62 temporary residents (second residence owners) that participated in the survey, the sample's representativeness is assured with respect to permanent residence. Indeed, the marked dissimilarity in the number of permanent and temporary residents closely matches the actual ratio between both groups at the time the questionnaire was on-line (on average 86\% of the coastal population in September are permanent residents, according to data of West Flanders Economic Agency $\left.{ }^{(18)}\right)$. The overall mean age of the 
sample is 54.6 years old, which is slightly biased towards older people (average age in Belgium is 49 years among adults (> 18 years old)). Male respondents are overrepresented $(65.1 \%)$. As regards flood experience, only $7 \%$ of the sample has suffered financial/material damage from previous flooding.

\subsection{Analyses}

\subsubsection{Exploratory factor analysis}

Exploratory factor analysis with correlated factors (oblimin rotation) revealed the existence of four factors among the questionnaire items, which corresponded to four constructs (cf. Table I). Since the items of information need were measured as dichotomies, they could not be included in the factor analysis. As far as the other items are concerned, all could be preserved except for one item regarding response efficacy of sea defense and actual protection level due to a low construct-loading. Internal consistencies (Cronbach's Alphas) were satisfactory for the four constructs. In order to facilitate further analysis, the items are summed together for each construct (plus information need), so that five scores are formed: (i) an information seeking behavior score (range: 4 - 20), (ii) a perceived knowledge score (range: $4-20$ ), (iii) a risk perception score (range: 5 -25), (iv) an response efficacy score (range: $2-10$ ), and (v) an information need score (range: $0-3$ ). For reasons of simplicity, the term "score" is not used in the remainder of the paper.

\subsubsection{Path analysis}

In order to test the set of hypotheses from Section 3, a path analysis is conducted using PRELIS 2.30 and LISREL 8.30 software. ${ }^{(43)}$ PRELIS was used to calculate the correlation and standard deviation matrices ${ }^{1}$ of the theoretical concepts as presented in the theoretical model $(n=243$ with list-wise deletion of cases). Both matrices then served as data input for the path analysis using LISREL, in which the covariance matrix was analyzed using maximum likelihood estimation. Multiple fit indices are reported to evaluate the adequacy of overall model fit. Adequate model fit is based on the $\mathrm{Hu}$ and Bentler cutoff criteria for fit indexes in covariance structure analyses. ${ }^{(44)}$ Preferably, the $\chi^{2} /$ degrees of freedom (df) ratio is smaller then 2, the Comparative Fit Index (CFI) is larger then 0.90, the Root Mean Square Error of Approximation (RMSEA) is smaller than 0.08 while the complete RMSEA 90 percent confidence interval is smaller than 0.10. Finally, the Standardized Root Mean square Residual (SRMR) should be smaller than 0.10 .

Besides overall model fit, LISREL output also generates standardized regression weights (i.e., $\beta$ 's) for hypothesized relationships among theoretical concepts, together with their significance levels in the form of so-called $t$-statistics. A $t$-statistic of 1.96 absolute or larger is significantly different from zero at the 0.05 level (two-sided). A $t$-statistic of 2.58 absolute or larger is significantly different from zero at the 0.01 level (two-sided). A single run of this LISREL model also allows the researcher to perform mediation tests. ${ }^{(45)}$ For mediation to be established three requirements must be fulfilled. First, there must be a relationship between theoretical concepts that is potentially mediated. In Figure 1 these hypothesized relations are referred to as total effect relations, and depicted in bold. Second, potentially mediated relationships must decrease in strength, after inclusion of one or more mediators in the model. These direct effects are standard output in a path analysis. Third, the difference between the total and direct effect is the so-called indirect effect. Mediation testing is done by investigating the significance of these single indirect effects in the case of one mediator or multiple indirect effects in the case of two or three mediators. ${ }^{(46)}$ Multiple indirect effects sum up to so-called total indirect effects, as produced by the LISREL software on demand. Direct and total indirect effects sum up to reported total effects. When total indirect effects are zero, then direct and total effects are alike. For example, based upon the theoretical model proposed in this study, efficacy directly predicts

\footnotetext{
${ }^{1}$ The correlation and standard deviation matrices are available from the first author upon request.
} 
information seeking behavior without intervening concepts. Direct and total effects should therefore be equal for the efficacy-behavior relationship.

\section{RESULTS}

Based upon the theoretical model, information seeking behavior is predicted by individual characteristics (H1a) and response efficacy (H1b). Based on a single run of the LISREL model, Figure 3 depicts the standardized regression weights ( $t$-statistics between brackets) for the total effects of individual characteristics and efficacy predicting information seeking behavior. The first hypothesis is confirmed, because information seeking behavior is enhanced when respondents are older, live permanently on the Belgian coast, and consider risk information useful. However, the total effects of previous flood experience and gender are not significantly related to information seeking behavior. Model fit was adequate with a $\chi^{2}$ of $11.08,7$ degrees of freedom, a $\chi^{2} / \mathrm{df}$ ratio of 1.58 , a CFI of 0.98 , a RMSEA of 0.048, an RMSEA confidence interval ranging from 0.00 to 0.10, and a SRMR of 0.037.

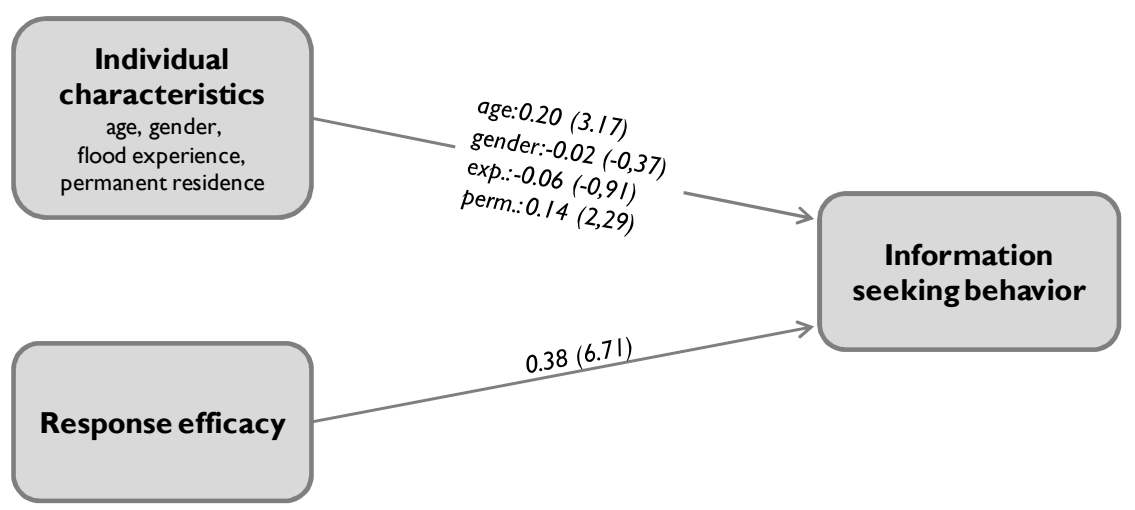

Figure 3 Unmediated model: $\beta$ values of total effects (t-statistics between brackets)

The LISREL output also allows us to test the second hypothesis concerning mediation. The total effects of age and residing permanently on information seeking behavior are mediated by risk perception (H2a), perceived hazard knowledge (H2b), and information need $(\mathrm{H} 2 \mathrm{c})$. Figure 4 depicts the standardized regression weights ( $t$-statistics between brackets) of all the direct effects in the mediated model. As can be seen in Figure 4, the direct effect of age on information seeking behavior remains significant, after controlling for multiple mediating processes. More importantly, the total indirect effect is significantly different from zero signaling partial mediation, $\beta_{\text {age total indirect effect }}=0.05$, $p<.05$. Careful inspection of the multiple intervening processes reveals that age is significantly associated with risk perception, but not with perceived hazard knowledge and information need ( $\beta_{\text {age }}$ total effect $=-0.03, n s$ ). Risk perception increases for older respondents. Risk perception in turn is significantly associated with information seeking behavior, $\beta_{\text {risk perception total effect }}=0.23, \mathrm{p}<.01$. Information seeking behavior is enhanced when risk perception increases. In sum, the total age effect on information seeking behavior is partly mediated through risk perception confirming H2a, but disconfirming hypotheses $2 \mathrm{~b}$ and $2 \mathrm{c}$. 


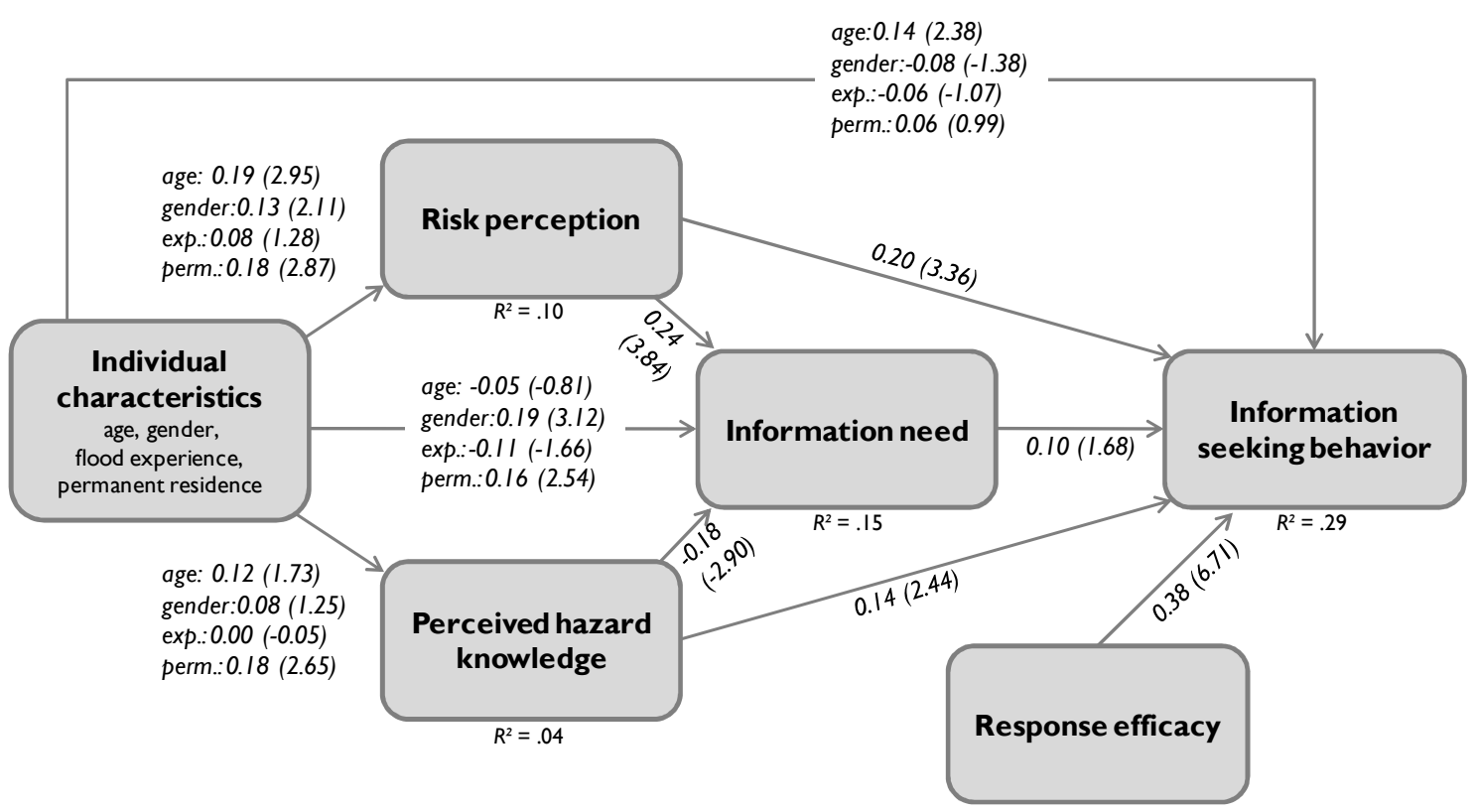

Figure 4 Mediated model: $\beta$ values of direct effects (t-statistics between brackets)

The direct effect of residing permanently on information seeking behavior is non-significant, while the total indirect effect differs from zero, $\beta_{\text {residence total indirect effect }}=0.08, p<.01$. A closer examination of the intervening processes reveals that residing permanently is significantly associated with risk perception, perceived knowledge, and information need ( $\left.\beta_{\text {residence total effect }}=0.17, p<.01\right)$. Residents living permanently on the Belgian coast have higher risk perception, higher perceived hazard knowledge, and greater information need, compared to temporary residents. As stated above, increasing risk perception increases information seeking behavior, $\beta_{\text {risk perception total effect }}=0.23, p<.01$. Similarly for perceived hazard knowledge, $\beta_{\text {knowledge total effect }}=0.12, \mathrm{p}<.05$. However, the association between information need and information seeking behavior is non-significant. In sum, the total effect of residing permanently on information seeking behavior is completely mediated through risk perception and perceived knowledge confirming $\mathrm{H} 2 \mathrm{a}$ and $\mathrm{H} 2 \mathrm{~b}$. Information need is not a mediator in this relationship, thereby disconfirming $\mathrm{H} 2 \mathrm{c}$.

Information need does not mediate the relationship between risk perception and information seeking behavior. The indirect effect was non-significant $\left(\beta_{\text {risk perception indirect effect }}=0.02, n s\right)$, thereby disconfirming H3a. Similarly, information need does not mediate the relationship between knowledge and information seeking behavior $\left(\beta_{\text {knowledge indirect effect }}=-0.02, n s\right)$, thereby disconfirming H3b. In sum, information need is again not a mediator due to the non-significant relationship with information seeking behavior.

According to $\mathrm{H} 4$, the individual characteristics under study (age, gender, flood experience and permanent residence) are expected to predict information need. This hypothesis is only partly confirmed, because information need is enhanced for men $\left(\beta_{\text {gender total effect }}=0.21, p<.01\right)$, and when respondents live permanently on the Belgian coast $\left(\beta_{\text {residence total effect }}=0.17, p<.01\right)$. However, the total effects of previous flood experience $\left(\beta_{\text {experience total effect }}=-0.09, n s\right)$ and age $\left(\beta_{\text {age total effect }}=-0.03, n s\right)$ are not significantly related to information need.

Finally, the total effects of residing permanently and gender on information need are mediated by risk perception (H5a), and perceived hazard knowledge (H5b). As can be seen in Figure 4, the direct effect of residing permanently remains significant on information need. The total indirect effect is nonsignificant $\left(\beta_{\text {residence total indirect effect }}=0.01, n s\right)$. Careful inspection of the intervening paths via risk perception and perceived knowledge explains this null effect. The intervening path through risk perception is positive while the intervening path through perceived knowledge is negative. Both 
indirect effects suppress each other, making the total indirect effect zero. A similar suppressor effect is found for the gender-need relationship. The total indirect effect is again non-significant, $\beta_{\text {gender total }}$ indirect effect $=0.02, n s$. In sum, residents living permanently on the Belgian coast and men have greater information need than temporary residents and women. Mediation processes via risk perception and perceived knowledge cancel each other out.

\section{DISCUSSION}

This study dealt with the public's information seeking behavior in the context of coastal flood risks. Based on previous information seeking models, empirical relationships were tested between information seeking behavior and a set of determinants. Particular attention was given to the mediating role of information need and the effects of residing permanently on the coast (or not) in the information seeking process. A sample of 313 respondents (inhabitants and second residence owners) was collected in the city of Ostend on the Belgian coast. Path analysis was used to statistically test several hypotheses, which reflected the different relationships of the hypothesized model (cf. Figure 1). This section discusses the main outcomes of the study and provides interpretations and additional clarification to these outcomes.

The first research objective of this study concentrated on the role of information need as being a mediator in the seeking process of risk related information. Previous models, such as RISP ${ }^{(9)}$ and FRIS ${ }^{(10)}$ suggested mediation by placing information need (or information insufficiency) in the centre of these models. However, our results suggest that information need does not fulfil a mediating role in the information seeking process. The direct effect from information need on information seeking behavior was non-significant. As a result, the indirect effects via information need were also nonsignificant. Our findings seem to support the outcome of Kahlor ${ }^{(1)}$, who could not find a significant effect of perceived knowledge insufficiency (comparable to information need) on seeking intentions either. Apparently, perceiving an information need does not necessarily result in higher seeking intentions. Responsibility might be the key variable to explain this insignificant relation. For instance, a person might feel he is insufficiently informed about a hazard, but beliefs it is not his/her responsibility to inform him(her)self about it. Instead, this person beliefs the government should actively communicate about risks. Previous research has examined similar relations. For example, Lindell and Perry ${ }^{(42)}$ reported significant correlations between perceived protection responsibility and the adoption of adjustments in the context of seismic hazards. To our knowledge, however, no study has yet investigated the moderating role of responsibility in the need-intention relationship. This might be a topic for future research.

The second research objective of this study focused on the effects of residing permanently in the coastal area or not, given that the temporary residents own a second home in the coastal area. Although both groups (inhabitants and second residence owners) have belongings to be concerned of in the coastal area, they largely differ in terms of "being present", making the temporary residents much more difficult to reach or to inform. The outcomes of our model suggested that permanent residents have higher risk perception, higher perceived hazard knowledge, and greater information needs than temporary residents. Most importantly, residing permanently or temporary along the coast affected information seeking behavior via risk perception and hazard knowledge, indicating full mediation. Hence, inhabitants are more than second residence owners inclined to seek for information on coastal flood risks, because they feel more vulnerable and have greater knowledge of the risks of coastal flooding. These outcomes suggest that temporary residents deserve extra attention in future flood risk communication.

In addition to the two research objectives, several other outcomes are worth mentioning here. In support of previous research by Kievik and Gutteling ${ }^{(6)}$, risk perception and response efficacy were found to be strong predictors of information seeking behavior. This outcome again suggests that risk communication should focus on raising risk perception (e.g., using fear appeal messages) together with persuasive messages to increase response efficacy. Apart from permanent residence, age was found the only strong predictor among the individual characteristics under study. The model indicated 
partial mediation since age predicts information seeking behavior both directly and indirectly via risk perception. This outcome supports previous studies on flood risk perception, which showed that older people generally exhibit higher levels of risk perception for such hazards. ${ }^{(19,30)}$ Finally, our study revealed no significant effects from flood experience on seeking intentions. We believe the small subsample of people having such experience $(N=18)$ prevented us from finding significant relations with other variables. Future studies should focus on collecting sufficient respondents with flood hazard experience to reliably investigate whether experience influences seeking intentions.

A specific issue encountered in our model is suppression of the total indirect effect via risk perception and perceived knowledge. We found such suppression effects for the relationships between gender, permanent residence and information need. While higher levels of risk perception increase information need, perceived hazard knowledge equally decreases information need. To our knowledge, no study previously reported on mediating processes opposing each other.

Some limitations of this study need to be acknowledged here. A first limitation concerns the model fit and the variance explained by the determinants. While our main goal was to examine several relationships between determinants of information seeking behavior, we believe the model we presented is adequate. Model fit parameters are satisfactory, just as the explained variance of information seeking behavior is (29\%). A higher explained variance might have been possible by inclusion of other variables (e.g., perceived responsibility). A second limitation deals with the response rate of the survey. As Lindell and Perry ${ }^{(42)}$ indicate, low response rates might make the representativeness of a sample uncertain because non-response might be systematic rather than random. We offer two main reasons for this low response rate. Due to privacy issues and the temporary subsample of second residence owners, it was not possible to invite people personally via email, nor was it possible to send out reminders. A third limitation concerns causality testing. Despite the suggested directions in our model, the cross-sectional nature of the data did not allow for causality testing. While we can rely on previous (quasi-) experimental studies and theories to assume that several directions are indeed correct (e.g., the causal effects of risk perception and response efficacy on information seeking behavior have been proven by Kievik and Gutteling ${ }^{(6)}$ ), caution should be made when linking up causal connections of specific relations. ${ }^{(30)}$ Finally, focus in this study was on information seeking behavior and its determinants. However, increasing information seeking behavior among citizens is only useful if it makes people more resilient and prepared for a hazard. Previous studies have already demonstrated strong links between information seeking intentions and preparedness behavior ${ }^{(\text {cf. }}{ }^{6-8)}$, but future research should further investigate the determinants and/or include the latter as well.

Despite these limitations, the present study provides new insights in the processes underlying people's information seeking behavior regarding coastal flood risks. Based on cross-sectional data, information need could not be detected as a mediator, nor as a predictor of information seeking behavior. This is important, since it shows that a high information need among the public not necessarily transfers itself into increased seeking intentions or even desirable behavior. Thus, although respondents from Ostend showed high information needs (92\% indicated more information on coastal flood risks is welcome, cf. Table I), governments should not rest on their laurels, since risk communication programs will be indispensable to fulfill the public's need. Moreover, it seems that people's information need is increasing in recent years, when comparing the current information need to the findings of the COMRISK project (in which $78 \%$ of the respondents indicated an information insufficiency) ${ }^{(15)}$ It seems reasonable to assume that recent defense works on the Belgian coast (e.g., extensive beach nourishments) have increased awareness levels among the public, which consequently have provoked their information need. Examining such (visual) effects might be a matter for future research.

Finally, this study showed that the lower information seeking behavior among temporary residents could be perfectly countered, since full mediation is present through risk perception and perceived knowledge. Communication campaigns should pay special attention to temporary residents, focusing on increasing their awareness and knowledge about coastal flood risks, thereby increasing their information seeking behavior indirectly. 


\section{ACKNOWLEDGEMENTS}

Financial support for this work was provided by Research Foundation - Flanders. The authors would like to thank the anonymous referees for their valuable comments and suggestions on earlier drafts of this paper.

\section{REFERENCES}

1. Schanze J. A Conceptual Framework for Flood Risk Management Research. In: J Schanze, editor, translator and editor Flood Risk Management Research - From extreme events to citizens involvement. Proceedings of European Symposium on Flood Risk Management Research (EFRM 2007). Dresden; 2007; p. 1-10.

2. Renn O. The role of risk perception for risk management. Reliability Engineering \& System Safety, 1998; 59 (1):49-62.

3. Ter Huurne EFJ, Gutteling JM. How to trust? The importance of self-efficacy and social trust in public responses to industrial risks. Journal of Risk Research, 2009; 12 (6):809-24.

4. Stewart RM, Rashid H. Community strategies to improve food risk communication in the Red River Basin, Manitoba, Canada. Disasters, 2011; 35 (3):554-76.

5. Renn O. White Paper on Risk Governance: Towards an Integrative Approach. Geneva, Switzerland: International Risk Governance Council (IRGC).

6. Kievik M, Gutteling J. Yes, we can: motivate Dutch citizens to engage in self-protective behavior with regard to flood risks. Natural Hazards, 2011; in press.

7. Mileti DS, Darlington JD. The role of searching in shaping reactions to earthquake risk information. Social Problems, 1997; 44 (1):89-103.

8. Paton D, Johnston D, Smith L et al. Responding to hazard effects: promoting resilience and adjustment adoption. Australian Journal of Emergency Management, 2001; 16 (1):47-52.

9. Griffin RJ, Dunwoody S, Neuwirth K. Proposed model of the relationship of risk information seeking and processing to the development of preventive behaviors. Environmental Research, 1999; 80 (2):S230-S45.

10. Ter Huurne E. Information seeking in a risky world. The theoretical and empirical development of FRIS: A Framework of Risk Information Seeking [PhD]: University of Twente; 2008. 170 p.

11. Kahlor L. PRISM: A Planned Risk Information Seeking Model. Health Communication, 2010; 25 (4):345-56.

12. Griffin RJ, Yang Z, ter Huurne E et al. After the flood - Anger, attribution, and the seeking of information. Science Communication, 2008; 29 (3):285-315.

13. Ter Huurne E, Gutteling J. Information needs and risk perception as predictors of risk information seeking. Journal of Risk Research, 2008; 11 (7):847-62.

14. Mertens T, Verwaest T, Delgado R et al. Coastal Management and Disaster Planning on the Basis of Flood Risk Calculations. In Proceedings of Coastal Engineering 2010. Shanghai, China; 2010.

15. Kaiser G, Reese S, Sterr H et al. COMRISK subproject 3: Public perception of coastal flood defence and participation in coastal flood defence planningSchleswig-Holstein State Ministry of the Interior - Coastal Defence Division.

16. Burby RJ, Wagner F. Protecting tourists from death and injury in coastal storms. Disasters, 1996; 20 (1):49-60.

17. Faulkner B. Towards a framework for tourism disaster management. Tourism Management, 2001; 22 (2):135-47.

18. Gunst C, Vandenbroucke L, Verhaeghe A. Tweede verblijven in breedbeeld. West-Vlaanderen Werkt, 2008; 3:14-21.

19. Kellens W, Zaalberg R, Neutens T et al. An Analysis of the Public Perception of Flood Risk on the Belgian Coast. Risk Analysis, 2011; 31 (7):1055-68.

20. Eagly AH, Chaiken S. The Psychology of Attitudes. San Diego: Harcourt Brace; 1993. 
21. Azjen I. The theory of planned behavior. Organizational Behavior and Human Decision Processes, 1991; 50:179-211.

22. Griffin RJ, Neuwirth K, Dunwoody $S$ et al. Information sufficiency and risk communication. Media Psychology, 2004; 6 (1):23-61.

23. Fischhoff B, Slovic P, Lichtenstein S et al. How Safe is Safe Enough - Psychometric Study of Attitudes towards Technological Risks and Benefits. Policy Sciences, 1978; 9 (2):127-52.

24. Slovic P. Perception of Risk. Science, 1987; 236 (4799):280-5.

25. Slovic P, Finucane ML, Peters E et al. Risk as analysis and risk as feelings: Some thoughts about affect, reason, risk, and rationality. Risk Analysis, 2004; 24 (2):311-22.

26. Terpstra T, Gutteling JM, Geldof GD et al. The perception of flood risk and water nuisance. Water Science and Technology, 2006; 54 (6-7):431-9.

27. Miceli R, Sotgiu I, Settanni M. Disaster preparedness and perception of flood risk: A study in an alpine valley in Italy. Journal of Environmental Psychology, 2008; 28 (2):164-73.

28. Trumbo CW. Information processing and risk perception: An adaptation of the heuristicsystematic model. Journal of Communication, 2002; 52 (2):367-82.

29. Armas I, Avram E. Perception of flood risk in Danube Delta, Romania. Natural Hazards, 2009; 50 (2):269-87.

30. Lindell MK, Hwang SN. Households' perceived personal risk and responses in a multihazard environment. Risk Analysis, 2008; 28 (2):539-56.

31. Kreibich H, Thieken AH, Grunenberg $\mathrm{H}$ et al. Extent, perception and mitigation of damage due to high groundwater levels in the city of Dresden, Germany. Natural Hazards and Earth System Sciences, 2009; 9 (4): 1247-58.

32. Lara A, Sauri D, Ribas A et al. Social perceptions of floods and flood management in a Mediterranean area (Costa Brava, Spain). Natural Hazards and Earth System Sciences, 2010; 10 (10):2081-91.

33. Keller C, Siegrist M, Gutscher $\mathrm{H}$. The role of the affect and availability heuristics in risk communication. Risk Analysis, 2006; 26 (3):631-9.

34. Knocke ET, Kolivras KN. Flash flood awareness in southwest Virginia. Risk Analysis, 2007; 27 (1):155-69.

35. Siegrist M, Gutscher H. Flooding risks: A comparison of lay people's perceptions and expert's assessments in Switzerland. Risk Analysis, 2006; 26 (4):971-9.

36. Grothmann T, Reusswig F. People at risk of flooding: Why some residents take precautionary action while others do not. Natural Hazards, 2006; 38 (1-2):101-20.

37. Thieken AH, Petrow T, Kreibich $\mathrm{H}$ et al. Insurability and mitigation of flood losses in private households in Germany. Risk Analysis, 2006; 26 (2):383-95.

38. Charlier RH, Demeyer CP. Tourism and the Coastal Zone - the Case of Belgium. Ocean \& Coastal Management, 1992; 18 (2-4):231-40.

39. Mertens T, De Wolf P, Verwaest T et al. An integrated master plan for Flanders future coastal safety In 31st International Conference on Coastal Engineering: Meeting Coastal Challenges. Hamburg, Germany; 2008.

40. Terpstra T. Emotions, trust and perceived risk: Affective and cognitive routes to flood preparedness behavior. Risk Analysis, in press; in press.

41. Terpstra T. Flood Preparedness: Thoughts, Feelings and Intentions of the Dutch Public [Doctoral Thesis]. Twente: University of Twente; 2010. 163 p.

42. Lindell MK, Perry RW. Household adjustment to earthquake hazard - A review of research. Environment and Behavior, 2000; 32 (4):461-501.

43. Jöreskog KG, Sörbom D. LISREL 8 user's reference guide. Chicago: Scientific Software International; 1993.

44. Hu L, Bentler PM. Cutoff criteria for fit indexes in covariance structure analysis: Conventional criteria versus new alternatives. Structural Equation Modeling, 1999; 6:1-55.

45. Baron RM, Kenny DA. The moderator-mediator variable distinction in social psychological research: Conceptual, strategic, and statistical considerations. Journal of Personality and Social Psychology, 1986; 51:1173-82.

46. Preacher KJ, Hayes AF. Asymptotic and resampling strategies for assessing and comparing indirect effects in multiple mediator models. Behavior Research Methods, 2008; 40:879-91. 